\title{
Sindhi Patchwork, Artisans and Fashion Industry
}

\author{
Lei Shen and Muhammad Hussnain Sethi* \\ School of Design, Jiangnan University, China
}

*Corresponding author: Muhammad Hussnain Sethi, School of Design, Jiangnan University, Wuxi, 214122, China.

\begin{abstract}
Food, apparel and shelter are the basic human needs. The apparel industry is massive since it satisfies the second basic human need. At present, it is worth 480 billion dollars and is projected to hit 700 billion dollars in a couple of years eventually. The reason explained behind this is that everyone is getting conscious of the way they look. Clothing has become a mean of creating an impression and people want to wear the latest fashionable clothes to portray their personality. However, the matter of concern is that due to the human desire to wear beautiful and fashionable clothes, 'fast fashion' industry has come into existence, causing the destruction to the world's resources and environment. Fashion Industry is among the top three polluters on the earth and produces almost 92 million tons of waste every year. In addition, 20 percent of the world's freshwater pollution is due to fabric treatment and dyeing. The clothing industry needs to play an important role in sustainable development, and researchers need to introduce more new and innovative ideas regarding sustainability to help the industry. There is a debate that patchwork design can be one of those steps that can lead the fashion industry towards sustainability and slow fashion. Patchwork has diverse forms across different countries and cultures. Few studies are available in other languages exploring Chinese, Korean and American patchworks, but no in-depth researches are available regarding the patchwork art of Indian Subcontinent. Thus, this study aims to explore Sindhi patchwork to highlight another delicate kind of patchwork, so the designers can take inspiration for their fashion collections from this artwork and help the fashion industry take baby steps towards sustainability.
\end{abstract}

\section{Literature Review}

The inexpensive and easily available fast-fashion products have changed people's behavior towards buying and disposing of clothing [1]. Fast-fashion has evolved as a powerful business paradigm and consumers are buying clothes more than ever now. Fast-fashion products are cheap, widely available and trendy, and thus people prefer them regardless of the impact on the environment [2]. There are several reasons for the rapid growth of the fast-fashion industry. The emergence of social media has played a vital role in this growth of this business model $[3,4]$.

Debatably, the fast fashion model is a good idea for millions of people all around the planet. People demand new, trendy, and reasonably priced, garments available in stores every week.

The fast-fashion industry has played a vital role in the world economy [5,6]. Over 300 million people are working in this industry at the moment. It has created millions of jobs and offered

employment to workers from developing countries. However, the cost our planet is paying is higher than that. The fast-fashion industry has a disastrous impact on the environment of our planet. This industry is responsible for nearly two billion tons of carbon dioxide and eight percent of greenhouse gas emissions worldwide [7]. Twenty percent of the world's water waste is produced by the fashion industry. Annually, it uses roughly 100 billion cubic meters of water $[8,9]$. Therefore, the need of the hour is to take sustainability in fashion industry seriously. Since the sustainability debate began, many brands and designers worldwide have participated in sustainability campaigns and present many ideas in their fashion collections that can help to lead the industry towards sustainability and one of them is using patchwork technique $[10,11]$. Due to this, patchwork is becoming a fashion more than tradition these days. Patchwork is a method of stitching different pieces of used or new fabrics together to create a larger piece of 
cloth. Traditional patchwork is mostly used to make quilts, wall hangings, rugs, covers, jackets, traditional dresses or other clothing items. Patchwork art began thousands of years ago before the revolution of technology. People had not much textile privilege, and they used to stitch various materials together with needles to make a bigger piece of cloth. Different regions have different patchwork techniques and designs, and there are few studies available that discuss American, Chinese and Korean patchwork, but not many detailed studies are documented on the patchwork of the Indian subcontinent. Our research goal is to explore the patchwork from the Sindh region of Pakistan, locally known as Rilli. Rilli is also made in Gujrat and Rajasthan region of India [12].

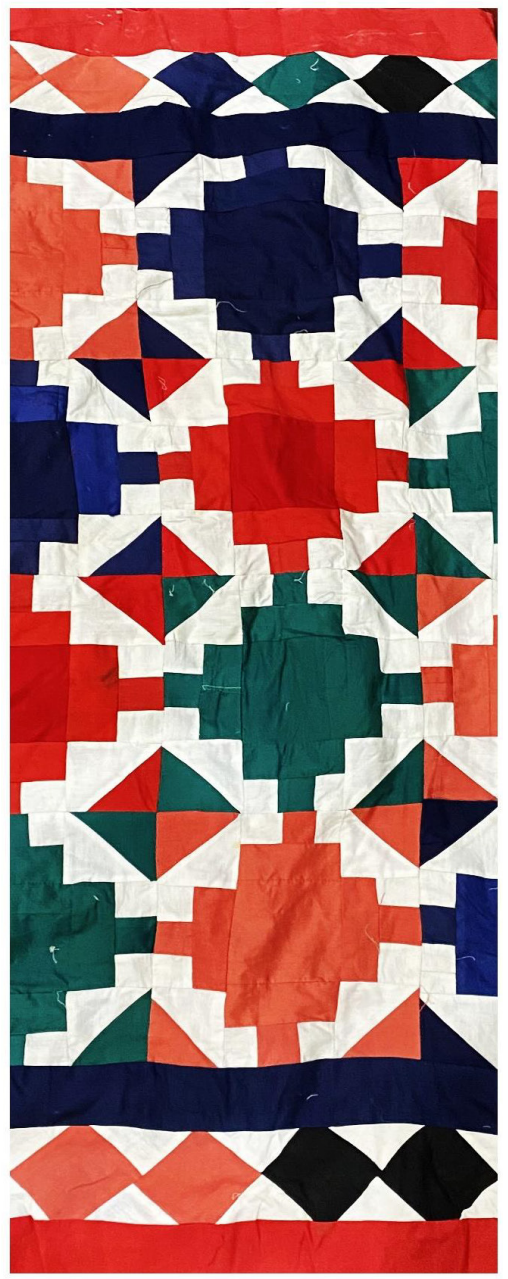

Figure 1: Patchwork Style Rilli.

Sindh has a long history of cultural heritage, and Sindhi traditional textile products, such as ajrak, patchwork, waistcoats, shawls are famous worldwide $[13,14]$. Sindhi patchwork is one of the most popular types of patchwork in the world. It originated in the Sindh region of Pakistan but has gained popularity all over the world. Sindhi patchwork is called Rilli, and women from remote and village areas create and sell this beautiful type of art to meet their living expenses [15]. Rilli has three kinds, including patchwork, applique, and embroidered, but on the whole, all of them are called
Sindhi patchwork. Patchwork rilli is based on colored pieces fabric cut into various geometric shapes and sewn together. Most of the patchwork designs are symmetrical and cautiously stitched. The sizes of the fabric pieces vary and some of them could be less than an inch (Figures 1\&2).

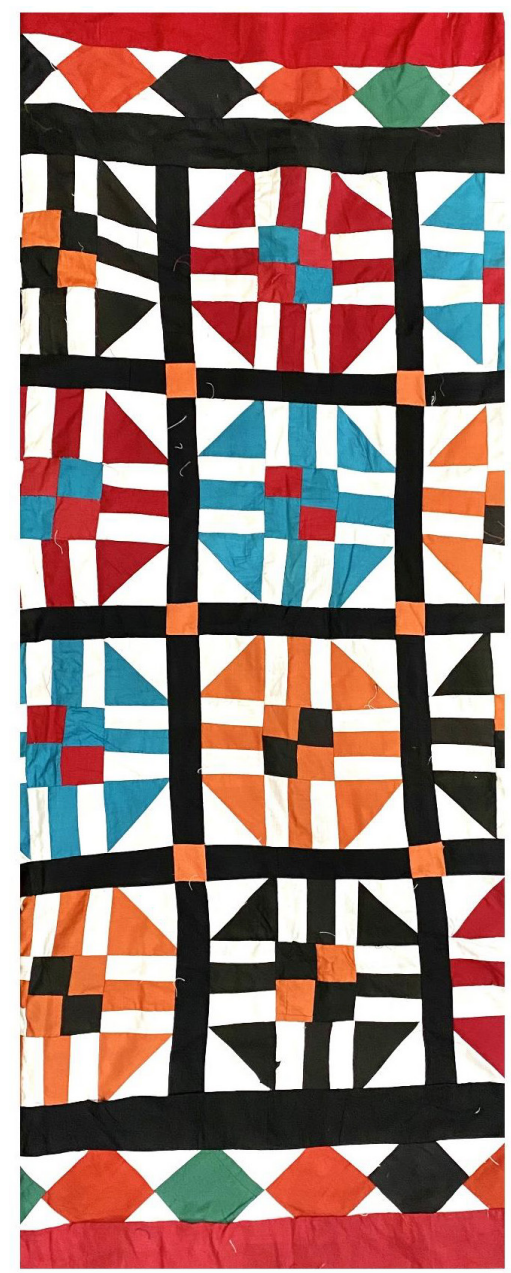

Figure 2: Patchwork Style Rilli.

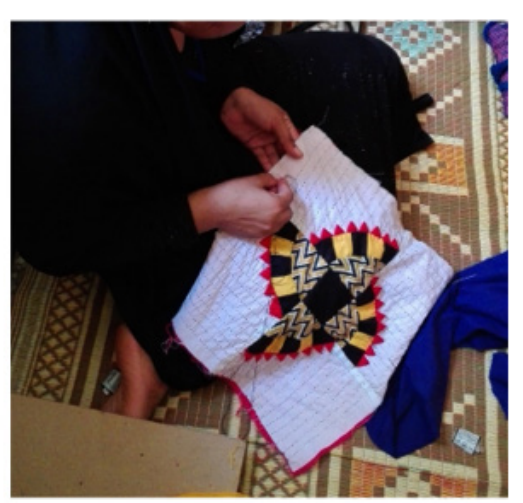

Figure 3: Women making applique design Rilli.

Appliqué rilli are made from small fabric sewn to another larger piece of cloth. It is mostly used to decorate the already made quilt or bedsheet.". Embroidered type or ralli design use embroidery as 
decoration or embellishment. A larger piece of patched or whole cloth is embroidered by using different colored threads. The embroidered rilli is filled with various stitches similar to those in "western" embroidery, and other special stitches used in this area. Sindhi people use rilli in home textiles such as a bedsheet, quilt cover, curtain, cushion, etc. [12] (Figure 3\&4).
There are special kinds of rillis made specifically for wedding and women use embellishing material to decorate them. There are many kinds of traditional Sindhi clothes, but lately, locals have started to introduce Sindhi patchwork in clothing as well. In order to satisfy both conventional and contemporary color schemes, the small pieces of fabrics are hand dyed [12] (Figure 5).

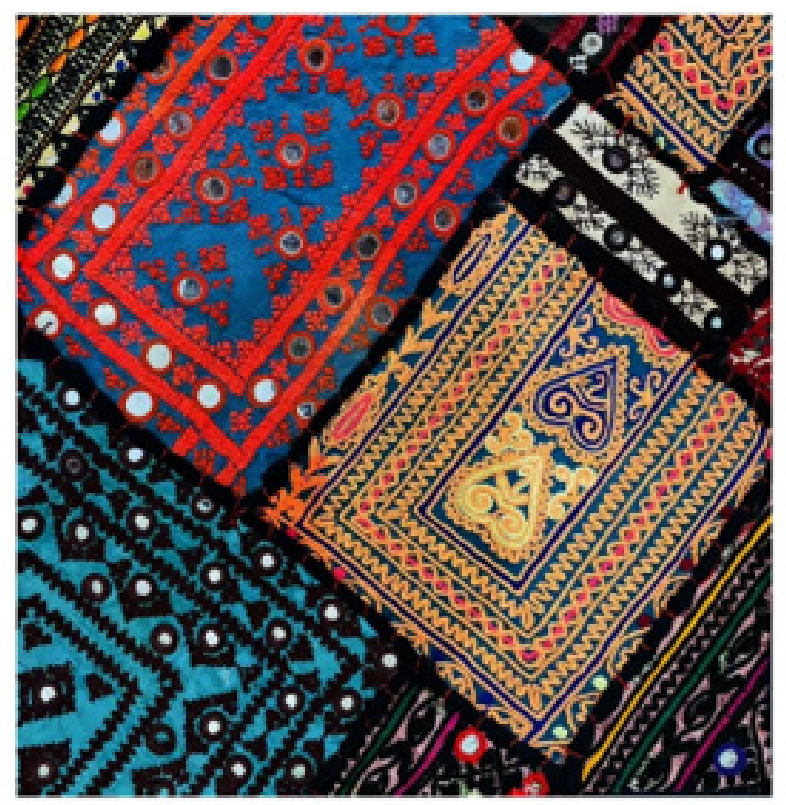

Figure 4: Embroidered design Rilli.

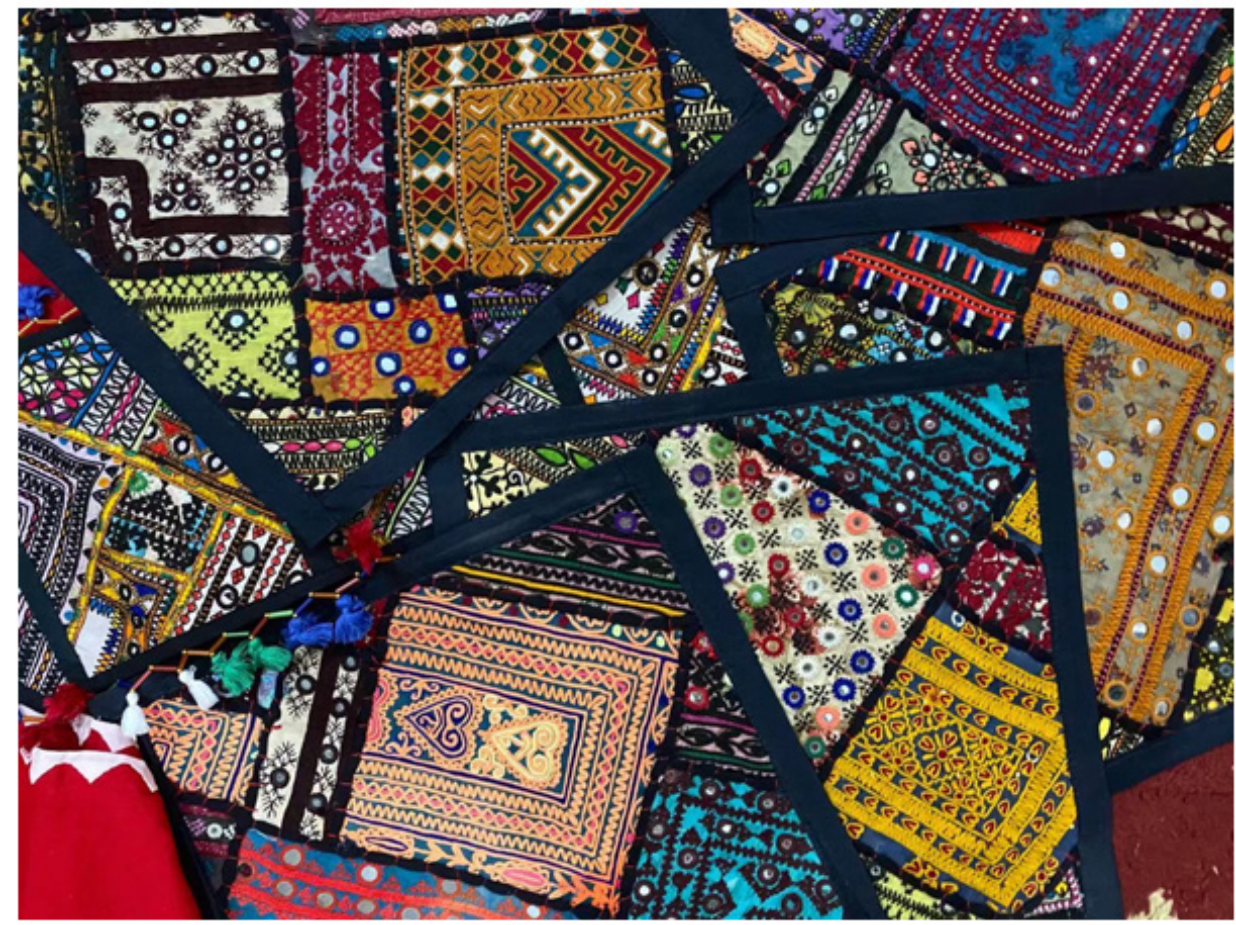

Figure 5: Special Rilli design samples. 


\section{Sindhi Patchwork Methods}

The fabric used to make Rilli is usually cotton fabric, but any material can be used according to the requirements. Women stitch old or new pieces of colored fabric with needles. It takes 4-5 days to make one rilli, but artisans get less than 2-3 dollars for one piece; therefore, young girls need to work with their mothers to make bread and butter.

\section{Fabric selection}

The first step is the fabric selection. Artisans choose the fabric according to their customer's demand. The common material that is used to make quilts is cotton whereas sometimes a customer wants rillis made by using other fabrics such as linen, silk and velvet. The handling of a few materials can be tough.

\section{Design development}

The next step is the design development. Women from rural areas who make the rillis rely on their memories because the skill has passed through generation to generation. Women do not use any tracing paper or any other tools to create designs and patterns. There is a lot of variety of rilli patterns and styles. The women are so skillful that they can make any style of rilli customer demand by showing them pictures or already made rilli.

\section{Sindhi patchwork in modern clothing}

Designers all around the world have used traditional or contemporary patchwork in their fashion clothing. Pakistani and Indian designers have also used Sindhi traditional elements in their clothing design, but one area that hasn't been explored in detail is Sindhi patchwork. Sindhi people use Sindhi patchwork as a quilt, quilt cover, bedding cushion or curtains but like many other patchworks, Sindhi patchwork can also be introduced in modern clothing. Designers can use any kind of Sindhi patchwork in their clothing. They can use simple patchwork, applique or embroidery design by reusing old threads and fabrics.

\section{Patchwork artisans}

We visited Sindh to learn about this patchwork art in detail. We found out that Sindhi Patchwork is usually created by poor artisans from remote areas of Sindh. Patchwork making is timeconsuming and hard-working effort. It takes 4 to 5 days to complete one patchwork quilt, but their price is extremely low. They sell it around 2-3 dollars per quilt. Families who make patchwork usually don't have other livelihood sources, so they are compelled to sell their art at a lower price. Competition and poverty in these areas are too much, and if one raises the price, people buy it from the others because poor people of this region can sell it at a very low cost. The shopkeepers who buy from to sell it to their consumers pay very little money. We spent a day exploring patchwork artists and interviewed an artisan to know about the things that are not known to many. Her name was Zeba bibi. She shared details about patchwork, its history, design and her life experiences without any hesitation. She was interviewed in the Sindhi language, and one of our research team members translated her interview in English. Interview duration was 98 minutes.

\section{Interview}

Zeba Bibi, a 66 years old woman, told us that she has been making patchwork quilts for almost 55 years, and her family has been making and selling patchworks for over a hundred years. Zebi has three sons and five daughters, and her caste was famous in Khairpur because of their patchwork skills She, along with her five daughters and three daughters in law work together and make as many patchwork quilts as they can to earn their livelihood. She told us they make all three types of Sindhi patchwork, and it takes at least 4 to 5 days for one woman to make a patchwork quilt. One woman of the family can hardly make seven quilts in a month. She explained that the family's males occasionally work as laborer's and help them sell quilts in the market or on the roads. On asking, why did they choose patchwork quilts as their livelihood she told us that they don't have other skills and they have been doing this business for centuries. The skills were transferred from their forefathers to the younger generations (Table $1 \&$ Figure 6).

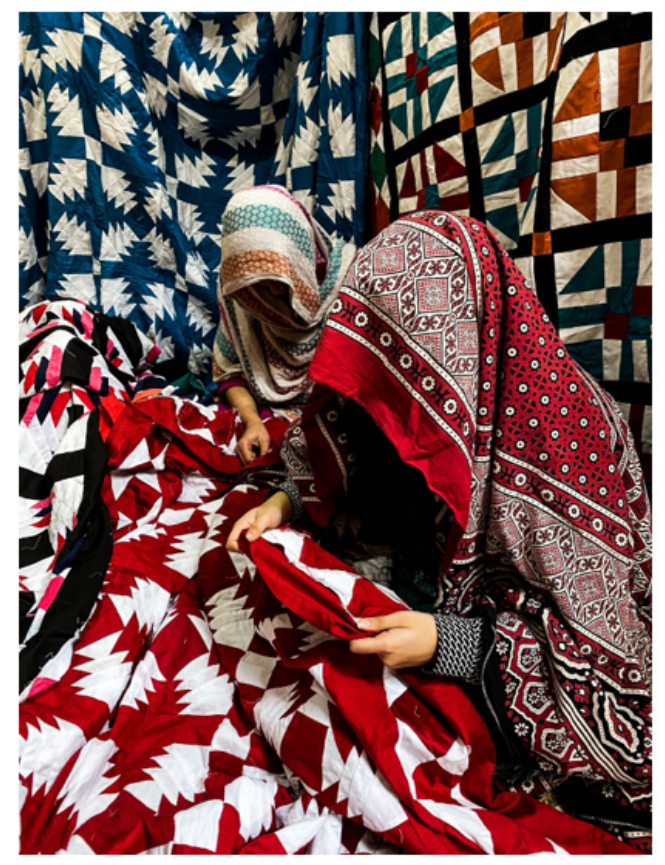

Figure 6: Sindhi women making different patchwork quilts. 
Table 1: Interview Questions

\begin{tabular}{|c|}
\hline Interview Questions: \\
\hline Please introduce yourself. \\
\hline What kind of patchwork do you make? \\
\hline How many types of patchwork are there? \\
\hline Why do you choose to make patchwork quilts? \\
\hline How educated are women here in Sindh who make patchwork quilts? \\
\hline How much a patchwork artist earns every month? \\
\hline How do people treat patchwork artists? Are patchwork making women well respected in society? \\
\hline What facilities government should provide to the Sindhi artists, specifically patchwork artists? \\
\hline
\end{tabular}

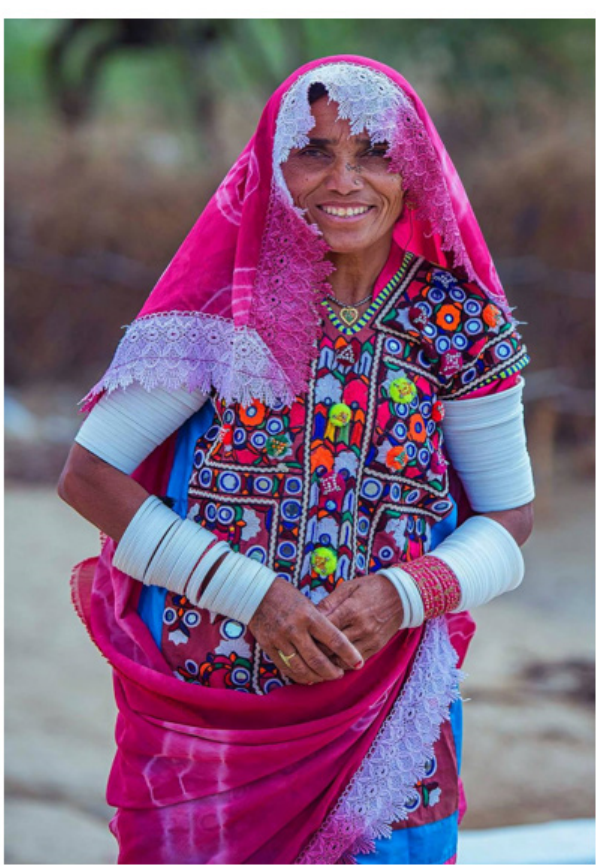

Figure 7: Zeba bibi wearing traditional costume.

It was stated that the average price of a quilt is 2 dollars when they sell it to retailers, but if they sell directly to consumers, they earn 6 dollars apiece. She added that children in this region begin working with their parents at a very early age to fulfil their household expenses. Due to poverty, parents can't afford the school fee of their children so rather than sending kids to school parents teach them skills so they can help their parents to earn a livelihood. She went on to explain that the highest education in that region is primary level education. No one from her family members has ever been to school. They can't even write their names. She mentioned that in Sindh, men also make patchwork quilts, but most women are involved in this business, since teaching different skills to girls is a culture in the subcontinent, and it is same in both rich and poor families. However, low-income families teach these skills to their girls not as a culture but for earning money as well. She expressed that despite the hard work of creating beautiful artworks and efforts toward preservation of this art, they don't earn well or get any recognition at the national or international level. She told us that the government doesn't do anything to facilitate them or providing them with opportunities to sell their products on fairs and exhibitions. She said whenever international tourists visit these areas they always praise their skill and buy quilts at a very good price, and therefore they think the government should organize exhibitions in big cities where they can display and sell their work (Figure 7).

\section{Conclusions and Discussion}

With growing attempts to reduce the environmental effects of the fashion industry, designers and consumers are looking for new ways to renew old garments. Fashion Industry plays a huge role in environmental pollution. Twenty percent of the world's waste is due to the fashion industry, and this sector is responsible for 10 percent of total annual carbon emissions. It takes 2700 liters of water to make one t-shirt, so we need more ideas to save our resources for us and our later generations. Therefore, we need to take sustainability seriously and introduce new ideas that can lead us towards sustainable fashion. In order to take steps towards sustainability, it is the responsibility of designers to promote sustainable trends because designers are the trendsetters. Fashion designers need to promote the trends of reusing old products rather than burning or disposing of them. Designers have been utilizing new concepts in recent years that can contribute towards sustainable fashion, and patchwork technique is among them. There are studies available discussing the traditional patchwork from different countries, but Sindhi patchwork hasn't been discussed much. Hence, we explored Sindhi patchwork, and since patchwork is becoming a trend, Sindhi patchwork can also be used in modern clothing and play an important role in reducing the environmental impact because the colors and designs of this special kind of patchwork are so elegant. Sindhi patchwork is different than Chinese, Korean, American and other traditional patchwork. The designs, shapes, and pattern are unique, colorful and eye-catching. There are different patchwork techniques that can be hand-made or made with the machines. There are a wide variety of stitches available in embroidered patchwork. Sindhi patchwork artisans work so hard to preserve this art, but their earnings are so little, and they cannot afford any luxuries [16]. They can't even the tuition fees for their kids.

Consequently, there are many benefits of exploring and using this patchwork art in modern clothing. The artisans can be helped, 
the cost to buy new clothes every now and then can be saved, new innovative designs can be tried and above all the waste of textile industry can be reduced as well. This paper's basic purpose was to explore the beautiful art of Sindhi patchwork and document it, so other researchers and our industry can benefit from it.

\section{Funding}

This research was supported by the China scholarship council (Project No. 201806795029) and the Ministry of education in China project of Humanities and Social Sciences (Project No. 19YJC760096).

\section{Acknowledgement}

This research would not have been possible without the help and support of the following people:

All the patchwork artisans who participated in this study. We are really thankful. Without your cooperation, this important article would not have been possible. My Grandmother Asmat Sitara Sethi. Thank you very much for guiding us about the cities and introducing us with women who allowed us to take the pictures. Mr. Anees-ur-Rehman Sethi and Ms. Sarwat Anees. Thank you for your support and guidance about Sindh. Ms. Rubab Asif. Thank you for your support and for helping us taking notes. Mr. Azhar Hafeez, Photographer, Pakistan Television Network, Islamabad, Pakistan. Thank you for capturing incredible pictures.

\section{Conflict of Interest}

The authors declared no potential conflicts of interest with respect to the research, authorship, and/or publication of this article.

\section{References}

1. Cachon GP, Swinney R (2011) The value of fast fashion: Quick response, enhanced design, and strategic consumer behavior. Management science 57(4): 778-795.
2. Jang J, Ko E, Chun E, Lee E (2012) A study of a social content model for sustainable development in the fast fashion industry. Journal of Global Fashion Marketing 3(2): 61-70.

3. Koivulehto EI (2017) Do social media marketing activities enhance customer equity? A case study of fast-fashion brand Zara.

4. Michaela E (2015) Fashion conscious consumers, fast fashion and the impact of social media on purchase intention. Academic Journal of Interdisciplinary Studies 4(3 S1): 173.

5. Hayes S, Jones N (2006) Fast fashion: a financial snapshot. Journal of Fashion Marketing and Management 10(3): 282-300.

6. Hausman WH, Thorbeck JS (2010) Fast fashion: Quantifying the benefits, in Innovative quick response programs in logistics and supply chain management Springer: 315-329.

7. Niinimäki K, Peters G, Dahlbo H, Perry P, Rissanen T, et al. (2020) The environmental price of fast fashion. Nature Reviews Earth \& Environment 1(4): 189-200.

8. Brewer MK (2019) Slow Fashion in a Fast Fashion World: Promoting Sustainability and Responsibility. Laws 8(4): 24.

9. Zamani B, Sandin G, Peters GM (2017) Life cycle assessment of clothing libraries: can collaborative consumption reduce the environmental impact of fast fashion? Journal of cleaner production 162: 1368-1375.

10. Kim S-Y (2009) Expressive Characteristics of Patchwork Shown in Modern Fashion. Journal of the Korean Home Economics Association 47(3): $1-9$.

11. Fletcher K (2013) Sustainable fashion and textiles: design journeys. 2013: Routledge, UK.

12. Stoddard PO (2003) Ralli Quilts: Traditional Textiles from Pakistan and India. Schiffer Pub.

13. Sethi MH, Shen L (2020) Ceramic art: The Kashi tiles of Sindh. Ceramics Art and Perception (115): 130.

14. Shen L, Sethi MH (2020) Wrinkles tell the story: The patchwork quilt of life. Ceramics Art and Perception (116): 116.

15. Nizamani B, Ram M, Nizamani DL (2019) Sindh handicrafts and socio-economic status of women. GSJ 7(2).

16. Khan FD (2011) Preserving the heritage: a case study of handicrafts of Sindh (Pakistan). 